\title{
Feasibility of neonatal screening for Duchenne muscular dystrophy
}

\author{
ROSALIND SKINNER,* ALAN E H EMERY,* GUNTER SCHEUERBRANDT, $\dagger$ \\ AND JAMES SYME +
}

From *the University Department of Human Genetics, Western General Hospital, Edinburgh; †CK-TestLaboratorium, Breitnau bei Freiburg, Germany; and $\ddagger$ the Eastern General Hospital, Edinburgh.

SUMMARY During the period November 1976 to September 1980, 2703 babies born in one Edinburgh hospital were screened in the neonatal period by estimation of their serum creatine kinase levels for Duchenne muscular dystrophy. Among the 2336 male babies tested, none proved to be affected and only 16 required second specimens to be obtained. Overall the false positive rate in the study was $0.78 \%$.

This study confirms that neonatal screening for Duchenne muscular dystrophy is feasible in a British hospital setting and is here most conveniently carried out on the 5th day of life along with routine testing for phenylketonuria.

Duchenne muscular dystrophy (DMD) is the commonest form of muscular dystrophy, with an incidence which approaches 1 in 3000 male births if ascertainment is complete. ${ }^{1}$ It is a serious $\mathrm{X}$ linked recessive disorder for which, at present, there is no effective treatment. The disease is characterised by progressive muscle wasting and weakness which first becomes clinically evident usually between the ages of 3 and 6 years and before 3.5 years in $95 \%$ of cases. ${ }^{2}$ The serum level of creatine kinase (SCK), however, is grossly raised in the preclinical stage and even from birth. ${ }^{34}$

The availability of a sensitive assay for creatine kinase activity in minute quantities of dried blood has made neonatal screening for DMD a practical possibility. ${ }^{5-8}$ Such screening can be justified on the grounds that if an affected boy could be detected sufficiently early and his mother proved to be a carrier and was given genetic counselling, a proportion of second cases in a family might well be prevented. It has been estimated that about 15 to $20 \%$ of cases might be prevented in this way.

This study was undertaken to determine the feasibility of neonatal screening for DMD in a defined British hospital population.

\section{Patients}

Beginning in November 1976 all liveborn babies born in the Eastern General Hospital, Edinburgh, were tested. However, for reasons discussed below it was decided after an initial experimental period to limit the study to liveborn male babies, and hence from May 1978 no further females were tested. Up to September 1980, 2703 babies have been screened of whom 367 were female and 2336 were male (table 1).

Since the test requires only a small specimen of dried blood it proved most practical in a British hospital setting for this to be done at the same time as the routine screening test for phenylketonuria. Thus, each baby was subjected to only one heel prick on about the 5th day of life and a spot of free flowing blood was dropped onto a separate filter paper card for the SCK screening test. The spot was then air dried. Any child who was discharged home with their mother before the standard 6th day was tested at home by the visiting Community Midwife using a card sent home with the mother from the nursery. The card was then posted to the laboratory.

\section{Methods}

The screening test for SCK activities in dried blood

TABLE 1 No of babies screened and those requiring repeat testing

\begin{tabular}{llll}
\hline & No screened & $\begin{array}{l}\text { No needing } \\
\text { repeat specimen }\end{array}$ & $\begin{array}{l}\text { No abnormal } \\
\text { on 2 tests }\end{array}$ \\
\hline Males & 2336 & $16^{*}$ & 0 \\
Females & 367 & 4 & 0 \\
Total & 2703 & 20 & 0 \\
\hline
\end{tabular}

* One further male baby with an initially raised SCK level died in the neonatal period before retesting was possible. 
spots has been described in detail previously. ${ }^{9}$ More recently this technique has been modified and made more sensitive. ${ }^{10}$ Discs of $3.2 \mathrm{~mm}$ diameter are punched out of the blood spots. These samples are then treated for about 30 minutes at $25^{\circ} \mathrm{C}$ with a solution containing adenosine monophosphate (AMP) and the luciferin-luciferase system of fireflies. During this preincubation time, the adenylate kinase (AK) of the erythrocytes transforms the adenosine triphosphate (ATP), which is equally present in the erythrocytes, to adenosine diphosphate (ADP). In a second step, the addition of ADP, of creatine phosphate, and of the AK inhibitor diadenosine pentaphosphate initiates the CK-catalysed reaction which synthesises new ATP. The increasing ATP concentration is monitored for 10 to 20 seconds by the luciferin-luciferase reaction which produces increasing intensities of visable light.

The SCK activity in $U / 1$ is obtained by comparison with dry blood samples of known activities. The relative standard deviation $\mathrm{CV}$ is about $\pm 10 \%$. The reaction scheme is shown in table 2 .

It was found that enzyme activity in dried blood specimens remained stable for up to 2 weeks at room temperature (provided direct heat or sunlight were avoided) without significant loss of enzyme activity. Thus, specimens could safely and conveniently be sent to the test laboratory by post.

If any specimen was found to have an SCK level of over $400 \mathrm{IU} / 1$ then the particular specimen was reassayed. If the level was still high then the SCKisoenzyme pattern was studied, since a predominantly CK-MM isoenzyme pattern might indicate a myopathy, whereas a predominantly CK-BB isoenzyme pattern would appear to be an inherited normal variation. ${ }^{11} \mathrm{~A}$ significantly raised SCK level, with a CK-MM isoenzyme pattern, in a second specimen would be an indication for further investigation of the baby with conventional serum enzyme determinations and perhaps also electromyography and muscle biopsy to seek evidence of a preclinical myopathy.

TABLE 2 Reaction scheme for the kinetic SCK screening test (whole blood test)

Step 1. Elimination of erythrocyte ATP by adenylate kinase (AK).

$$
A T P+A M P \simeq A K A D P
$$

Step 2. Measurement of creatine kinase activity (CK). CK reaction:

$\mathrm{ADP}+$ creatine phosphate $\mathrm{CK}$ ATP + creatine

ATP monitoring:

ATP + luciferin $+\mathrm{O}_{2} \stackrel{\text { luciferase }}{\longrightarrow} \mathrm{AMP}+\mathrm{PP}_{1}+\mathrm{CO}_{2}+$ oxyluciferin + light

\section{Results}

During the early experimental part of the study a lower cut-off level of SCK was used in the hope of also detecting carriers of DMD among the female babies. However, it became apparent that interpretation of the significance of a moderately raised level of SCK in a female neonate was far from clear. For this reason and because this lower cut-off level was generating a number of unnecessary requests for second samples which needlessly worried parents, testing of female babies was abandoned.

Of the 2336 male babies tested, 16 had SCKs high enough to warrant obtaining a second specimen, but none of these was found to have a significantly raised SCK level on retesting. One further male baby who proved to have an initially high SCK level associated with a predominantly CK-MM isoenzyme pattern died before a second specimen could be obtained. The cause of death was severe congenital heart anomalies. Of the 367 girls tested, four required a follow-up specimen. The overall false positive rate was therefore $0.74 \%$.

Since the introduction of more sensitive reagents in mid-1979 no false positives have been found in 850 who have so far been tested.

\section{Discussion}

This study has shown that in practical terms neonatal screening for Duchenne muscular dystrophy is feasible within the British health care system. The test used has proved an accurate and highly reliable method of detecting neonatal preclinical cases of DMD. ${ }^{5-7} 9$ In the present study the false positive rate was low $(0.74 \%)$ and could have been reduced further by testing the babies later, at about 4 to 6 weeks, when the frequently found rise in SCK in healthy newborns has usually returned to normal levels. In the voluntary screening programme in West Germany babies are tested between 4 and 6 weeks of age and the false positive rate is less than $0.2 \%{ }^{12}$ However, in practice it is more convenient in this country for babies to be tested at the same time as for phenylketonuria since there is no routine recall of healthy babies to hospital at any later time.

Pilot screening programmes have been carried out in West Germany, ${ }^{6}$ in New Zealand, ${ }^{8}$ and in the United States, ${ }^{\mathbf{5}}$ and screening has been taking place in the Rhône-Alpes region of France since 1975. ${ }^{13}$ All have shown routine neonatal screening for DMD to be feasible and at least 16 preclinical cases of DMD have been detected and confirmed by conventional investigations.

A privately financed voluntary programme is taking place in West Germany and any parents wishing to participate pay for the test themselves. It 
has been estimated that a test price of approximately DM 5.00 would be appropriate if carried out as part of a wide-scale population screening programme.

The ethics of population screening have been debated widely and at length. Traditionally a prime requirement is that there should be an effective treatment available for the affected subjects identified by such programmes. ${ }^{14}$

One of the main arguments against screening for DMD has thus been the absence of any proven effective treatment which could be offered to affected subjects. Nevertheless, there are considerable benefits to be gained by early detection of affected boys. Early genetic counselling of mothers found to be carriers before another pregnancy is under way may well prevent the occurrence of a second case in a family. It has been estimated that about 15 to $20 \%$ of all cases might be prevented in this way. Experience has shown that genetic counselling is very effective in families with DMD and few women wish to take the risk of having an affected child. ${ }^{15}$ It has been suggested that an alternative to neonatal screening would be to screen all boys not walking by 18 months of age. ${ }^{16}$ This would increase the detection rate but at the expense of some second cases occurring. The need for very careful and sensitive counselling of parents of proven positive cases is naturally of paramount importance. After counselling, comprehensive follow-up and support would be needed to help such parents. Another important advantage of early identification of affected boys is that if an effective treatment becomes available it might well be more effective if given at the earliest possible time, since there is now good evidence that signs of this disease are in fact already manifest in the fetus before 20 weeks' gestation. ${ }^{17}$

Finally, extensive surveys of parents in West Germany, the USA, and France showed that the large majority of parents are in favour of an early diagnosis. A recent study in the United Kingdom ${ }^{18}$ showed that $75 \%$ of parents of affected boys were clearly in favour of neonatal screening and early communication of the diagnosis. Clearly it might prevent many parents from enduring long and emotionally traumatic delays and unfounded reassurances which often precede the establishment of a diagnosis of DMD later in childhood. In addition, many families felt it would be an advantage to be able to prepare themselves and plan for a life later on with a handicapped child.

Thus, not only does neonatal screening for DMD appear to be feasible, it appears that such a programme might be thought desirable by the majority of parents.

We would like to thank Miss Linda Andruszczenko and the medical and nursing staff of the Nursery at the Eastern General Hospital, Edinburgh, for their invaluable help in the collection and organisation of the specimens.

This work was supported in part by a grant to AEHE from the Muscular Dystrophy Group of Great Britain.

\section{References}

1 Emery AEH. Duchenne muscular dystrophy. Genetic aspects, carrier detection and antenatal diagnosis. $\mathrm{Br} \mathrm{Med}$ Bull 1980;36:117-22.

2 Emery AEH, Skinner R. Clinical studies in benign (Becker type) X-linked muscular dystrophy. Clin Genet 1976;10:189-201.

3 Heych H, Laudahn G, Carsten PM. EnzymaktivitätsBestimmungen bei Dystrophia Musculorum progressiva. IV. Mitteilung über die Serumenzymkinetik im praklinischen Stadium des Typus Duchenne wahrënd der ersten 2 Lebensjahre. Klin Wochenschr 1966;44:695-700.

4 Pearson CM. Serum enzymes in muscular dystrophy and certain other muscular and neuromuscular diseases. N Engl J Med 1957;256:1069-75.

5 Zellweger H, Antonik A. Newborn screening for Duchenne muscular dystrophy. Pediatrics $1975 ; 55: 30-4$.

6 Beckmann R, Scheuerbrandt G. Screening auf erhöhte CK-Aktivitaten zur Frukerkennung der DuchenneMuskeldystrophie. Ergebnisse einer Studie an Blutproben von 166520 Neugeborenen. Kinderaerztl Prax 1976;7: 1267-72.

7 Dellamonica C, Robert JM, Cotte J, Collombel C, Dorche C. Systematic neonatal screening for Duchenne muscular dystrophy. Lancet $1978 ;$;i: 1100.

8 Drumond LM. Creatine phosphokinase levels in the newborn and their use in screening for Duchenne muscular dystrophy. Arch Dis Child 1979; 54:362-6.

- Beckmann R, Scheuerbrandt G, Antonik A, Antonik S. Ein neuer Kreatinkinase-Test. Kinderaerztl Prax 1974;5: 731.

10 Scheuerbrandt G, Lundin A. In preparation. 1980.

11 Arnold H, Lohr GW, Scheuerbrandt G, Beckmann R. Creatine kinase in human erythrocytes: a newly detected genetic anomaly. Blut 1978;37:249-56.

12 Scheuerbrandt G. Muscular dystrophy research; advances and new trends. Proceedings of International Symposium on Muscular Distrophy, Venice, 1980. Amsterdam: Excerpta Medica, 1980: 157-66.

13 Dellamonica C, Robert JM, Cotte J, Plauchu H, Dorche C. Dépistage néonatal systemastique de la myopathie de Duchenne de Boulogne. Nouv Presse Med 1979;8:1491-3.

14 Janeway CA. Screening for inherited diseases. $N$ Engl J Med 1971;284:787.

15 Emery AEH, Watt MS, Clack ER. The effects of genetic counselling in Duchenne muscular dystrophy. Clin Genet 1972;3:147-50.

16 Gardner-Medwin D, Bundey S, Green S. Early diagnosis of Duchenne muscular dystrophy. Lancet 1978;i:1102.

17 Emery AEH, Burt D, Dubowitz V, et al. Antenatal diagnosis of Duchenne muscular dystrophy. Lancet $1979 ; \mathbf{i}: 847-9$.

18 Firth M. Interviews with the parents of sufferers of Duchenne muscular dystrophy. Muscular Dystrophy Group of Great Britain 1980.

Requests for reprints to Dr R Skinner, Department of Human Genetics, Western General Hospital, Edinburgh EH4 2XU. 